\title{
A Case of Biliary Cast Developed in a Patient with Long-Standing Biliary Sludge
}

\author{
Ja Won Koo', Na Eun Jang', Hong Joo Lee ${ }^{1}$, Kwang Ro Joo', Jae Myung Cha', Hyun Phil Shin ${ }^{1}$, Joung II Lee ${ }^{1}$ \\ and Sung-Jig Lim² \\ Departments of ${ }^{1}$ Gastroenterology and ${ }^{2}$ Pathology, Kyung Hee University Hospital at Gangdong, Kyung Hee University School of Medicine, Seoul, Korea
}

Development of biliary casts is very unusual, especially in patients who have not undergone liver transplantation. Variable causes of biliary cast formation in nonliver transplantation patients have been suggested. However, stasis of bile flow and/or gallbladder hypocontractility is known to eventually result in the promotion of biliary sludge and subsequent cast formation. Here we present one case of biliary cast syndrome, which developed in a nonliver transplant patient who had biliary sludge for a long period of time, providing evidence that long-standing biliary sludge may lead to cast formation.

Key Words: Cast; Biliary tract; Sludge; Gallbladder; Nontransplant

\section{INTRODUCTION}

Biliary cast syndrome is defined as the presence of casts within the intra- and/or extrahepatic bile ducts, causing obstruction and cholangitis, eventually complicated by multiple strictures, ductal dilation, and/or liver microabscesses. ${ }^{1,2}$ This is an uncommon condition, but is more frequently described in liver transplant patients. ${ }^{3,4}$ Only a few reports have described biliary cast syndrome in nonliver transplant patients; these included patients with antiphospholipid antibody syndrome, B-cell non-Hodgkin lymphoma, cholecystectomy, and those who had undergone allogeneic hematopoietic stem cell transplantation. ${ }^{4-10}$ The exact pathogenesis of biliary casts remains uncertain; however, many factors have been suggested as playing an etiological role in their formation. Theoretically, anything that increases viscosity and/or hinders the flow of bile may precipitate cast formation. Therefore, biliary sludge is known to be a prerequisite for cast formation. ${ }^{4}$

Received: February 24, 2012 Revised: March 29, 2012

Accepted: March 29, 2012

Correspondence: Kwang Ro Joo

Department of Gastroenterology, Kyung Hee University Hospital at Gangdong, Kyung Hee University School of Medicine, 892 Dongnam-ro, Gangdong-gu, Seoul 134-727, Korea

Tel: +82-2-440-6111, Fax: +82-2-440-6295, E-mail: krjoo@khu.ac.kr

(a) This is an Open Access article distributed under the terms of the Creative Commons Attribution Non-Commercial License (http://creativecommons.org/ licenses/by-nc/3.0) which permits unrestricted non-commercial use, distribution, and reproduction in any medium, provided the original work is properly cited.
Here we present one case of biliary cast syndrome, which developed in a nonliver transplant patient who had biliary sludge for a long period of time, providing evidence that longstanding biliary sludge may lead to cast formation.

\section{CASE REPORT}

An 80-year-old man was admitted with a complaint of abdominal pain and fever. The patient's history included brain surgery due to head trauma approximately 1 year ago; he had remained in a bed-ridden state since then. The patient had a blood pressure of 109/66 mm Hg, a heart rate of 122 beats/ $\mathrm{min}$, a respiration rate of 30 breaths $/ \mathrm{min}$, and a body temperature of $38.4^{\circ} \mathrm{C}$. Physical examination revealed tenderness at right upper quadrant of abdomen. Laboratory examination revealed a hemoglobin of $14.2 \mathrm{~g} / \mathrm{dL}$ (normal range, 13 to 17 ); white blood cell, $29,900 / \mathrm{mm}^{3}$ (normal range, 4,000 to 10,000); platelet, $296,000 / \mathrm{mm}^{3}$ (normal range, 130,000 to 350,000 ); total bilirubin, $2.5 \mathrm{mg} / \mathrm{dL}$ (normal range, 0.22 to 1.2 ); aspartate aminotransferase (AST), 742 IU/L (normal range, <40); alanine aminotransferase (ALT), $422 \mathrm{IU} / \mathrm{L}$ (normal range, <40); alkaline phosphatase (ALP), 1,593 IU/L (normal range, 66 to 220); and $\gamma$-glutamyl transpeptidase 1,321 IU/L (normal range, 8 to 66). Abdominal computed tomography showed dilatation of the biliary tract and gallbladder at first. We performed percutaneous transhepatic cholecystostomy for the 
purpose of immediate decompression of the biliary tract. The patient became stable and his vital signs were stabilized. Follow-up tubography via percutaneous cholecystostomy showed multiple tubular filling defects in the extrahepatic bile

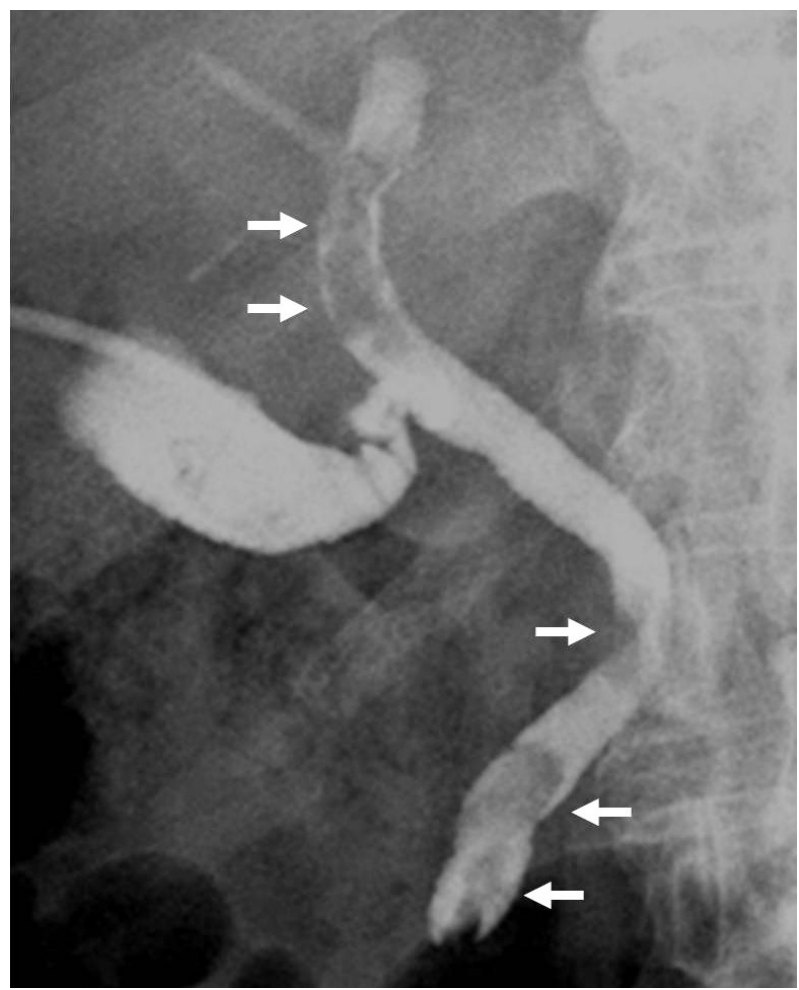

Fig. 1. Cholangiographic finding obtained by percutaneous cholecystostomy. Multiple filling defects (arrows) are noted in the extrahepatic bile duct.

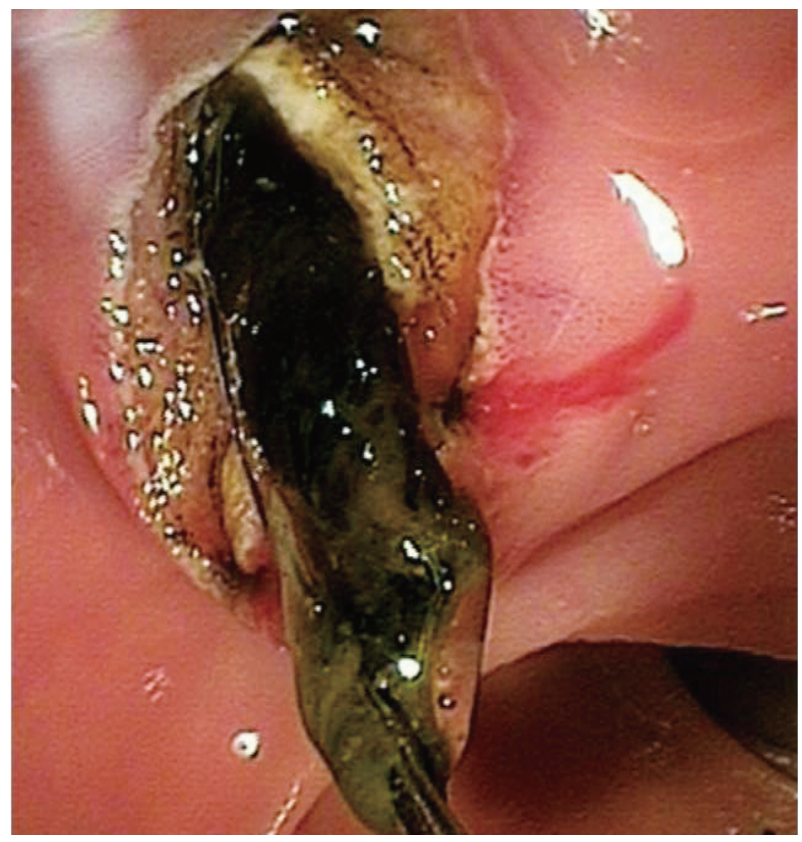

Fig. 2. Duodenoscopic finding during endoscopic retrograde cholangiopancreatography. Black-colored tubular structures were extracted from the bile duct with a retrieval basket. duct (Fig. 1). Endoscopic retrograde cholangiopancreatography (ERCP) revealed the same features; therefore, we performed endoscopic sphincterotomy followed by basket retrieval of the black colored tubular structures from the extrahepatic bile duct (Fig. 2). Histology of the biliary tubular structures showed aggregates of bile pigmented amorphous materials, consistent with biliary cast (Fig. 3). Within a few weeks after the ERCP, his liver blood tests had returned to normal. Currently, almost 16 months after the removal of the biliary cast, he was found to be asymptomatic and maintained a normal range of liver biochemistries.

One year before admission, he had suffered head trauma after falling from his bicycle. A head computed tomography scan showed acute subdural and subarachnoid hemorrhage. He underwent emergent brain surgery, followed by management in the intensive care unit (ICU) for several weeks. After that, he was stable but remained in a bedridden state. At approximately 1 month after the brain surgery, his liver bio-

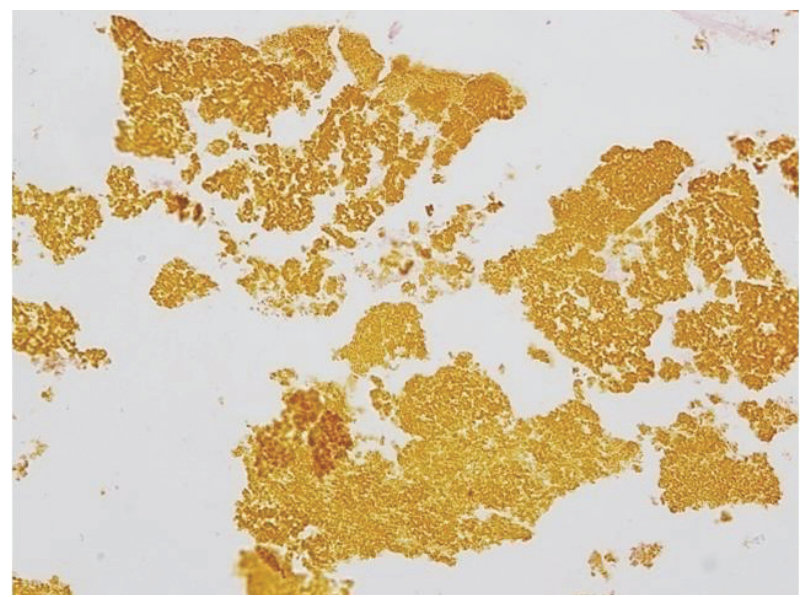

Fig. 3. Pathologic finding of the tubular structures. It shows aggregated bile pigmented amorphous materials, consistent with biliary cast (papanicolaou stain, $\times 100$ ).

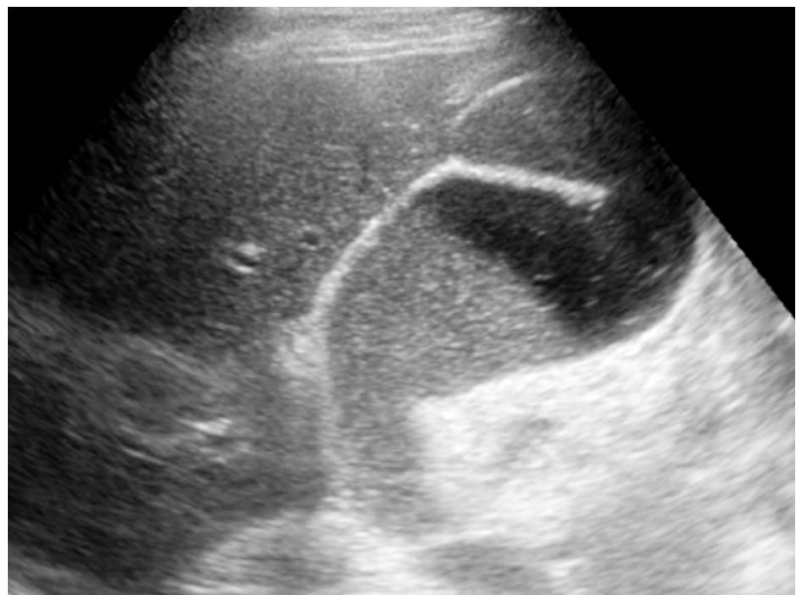

Fig. 4. Ultrasonographic finding, performed 1 year before admission. Gallbladder was distended and filled with a large amount of sludge. 

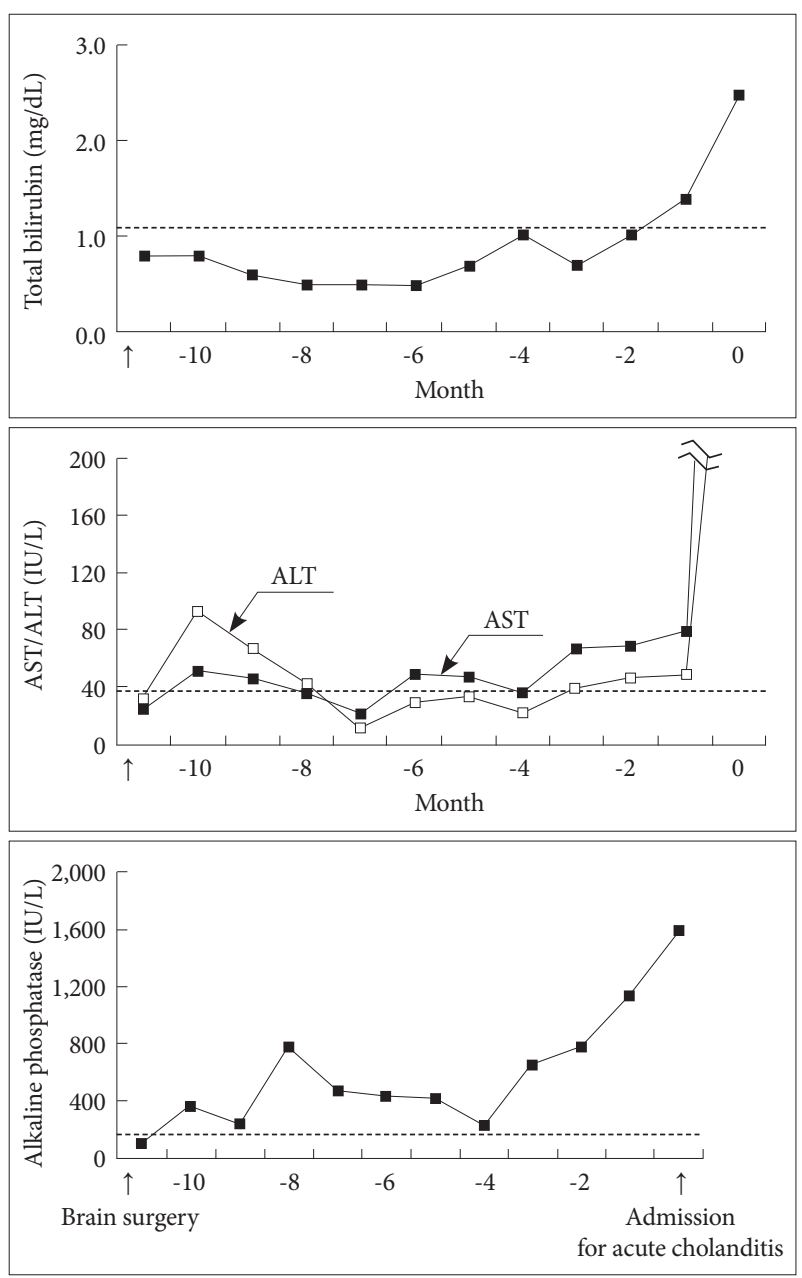

Fig. 5. Pattern of the patient's liver biochemistry during the past year, before admission for acute cholangitis. Dotted lines indicate the upper limit of the normal range of each value. AST, aspartate aminotransferase; ALT, alanine aminotransferase. chemistry, which had remained in the normal range since admission, began to deteriorate: a bilirubin of $0.5 \mathrm{mg} / \mathrm{dL}$, AST of $51 \mathrm{IU} / \mathrm{L}$, ALT of $92 \mathrm{IU} / \mathrm{L}$, ALP of $361 \mathrm{IU} / \mathrm{L}$, and $\gamma$-glutamyl transpeptidase of $525 \mathrm{IU} / \mathrm{L}$. We performed an investigation of possible causes for abnormal liver biochemistry, such as drugs, viral infections, and etc. However, an abnormal ultrasonographic finding, gallbladder distention filled with a large amount of sludge, was proven to be the only cause of abnormal liver biochemistry (Fig. 4). Despite abnormal liver biochemistry, the patient did not show acute cholangitis; in addition, he maintained stable vital signs and had no complaints. Considering the poor general status with bed-ridden state, he received only supportive care with intermittent blood tests. Fig. 5 shows the patient's liver biochemistry during the past year, showing wax and wane, with constant deterioration, since 4 months before developing acute cholangitis and being admitted to the hospital.

\section{DISCUSSION}

Pathophysiology of biliary cast formation is unclear; however, hepatic infarction, fasting related gall bladder hypocontractility, biliary infection, biliary ischemia due to hypotension induced sepsis, bile pigment load due to absence of a gallbladder after cholecystectomy, and benign biliary stricture are included in suggested factors for biliary cast formation in nonliver transplant patients. ${ }^{4-10}$ These conditions are eventually predisposed to hindrance of bile flow, and thereby result in biliary sludge formation. This case provided evidence to demonstrate that the presence of long-standing biliary sludge may lead to development of biliary casts. We initially noticed

Table 1. Summary of Reported Cases of Biliary Cast Syndrome in Nonliver Transplant Patients

\begin{tabular}{|c|c|c|c|c|}
\hline Author & Sex/Age & Characteristics & Suspected etiologies & Management \\
\hline$\overline{\text { D’Haens et al. }{ }^{5}}$ & $\mathrm{~F} / 89$ & Cholecystectomy & Increased bile pigment load & $\begin{array}{l}\text { ERCP, cholangioscopy, flushing } \\
\text { via percutanous transhepatic route } \\
\text { (incomplete removal) }\end{array}$ \\
\hline Byrne et al. ${ }^{6}$ & $\mathrm{~F} / 66$ & Brain contusion & Head trauma, ICU care, gallbladder sludge & ERCP, laparotomy, transplantation \\
\hline Katsinelos et al. ${ }^{7}$ & $\mathrm{M} / 76$ & Cholecystectomy, & Fasting, TPN, biliary infection & ERCP (complete removal) \\
\hline \multirow[t]{2}{*}{ Gleeson et $\mathrm{al}^{8}$} & $\mathrm{~F} / 25$ & $\begin{array}{l}\text { Antiphospholipid antibody } \\
\text { syndrome }\end{array}$ & Hepatic infarction and ischemia & ERCP (complete removal) \\
\hline & $\mathrm{M} / 67$ & $\begin{array}{l}\text { Non-Hodgkin lymphoma, } \\
\text { CLL }\end{array}$ & $\begin{array}{l}\text { Fasting, TPN, biliary infection, } \\
\text { ischemia }\end{array}$ & ERCP (complete removal) \\
\hline $\begin{array}{l}\text { Dziurkowska- } \\
\text { Marek et al. }{ }^{9}\end{array}$ & $\mathrm{M} / 69$ & - & $\begin{array}{l}\text { Travellers' diarrhea and biliary } \\
\text { infection }\end{array}$ & ERCP (incomplete removal) \\
\hline Hosoi et al. ${ }^{10}$ & $\mathrm{~F} / 36$ & $\begin{array}{l}\text { Myelodysplastic syndrome, } \\
\text { HSCT }\end{array}$ & Bile duct stricture, immune reaction & ERCP (complete removal) \\
\hline Present case & $\mathrm{M} / 70$ & Brain surgery, bed ridden state & Long-standing biliary sludge (1 yr) & ERCP (complete removal) \\
\hline
\end{tabular}

F, female; ERCP, endoscopic retrograde cholangiopancreatography; ICU, intensive care unit; M, male; TPN, total parenteral nutrition; CLL, chronic lymphocytic leukemia; HSCT, hematopoietic stem cell transplantation. 
gallbladder sludge in the patient at about 1 month after brain surgery. Development of gallbladder sludge can be explained by the brain surgery and an ICU setting, which both appear to be recognized risk factors for sludge formation due to gallbladder hypocontractility. ${ }^{11}$ The gallbladder sludge then migrated into the bile duct over a long period of time, which can be explained indirectly by long-standing and gradually increased abnormal liver biochemistry; biliary cast formation might then have developed and was observed as acute cholangitis in the present case.

There is no recommended standard management protocol for removal of biliary casts and each case should be viewed individually. Although data are limited, five of eight nonliver transplant patients (Table 1) underwent successful removal of biliary casts by ERCP only. Therefore, ERCP is thought to be a reasonable step to take prior to considering laparotomy, particularly in nonliver transplant patients. However, reports on liver transplant patients showed that endoscopic management was still effective only in $25 \%$ of liver transplant patients with cast formation and that many patients experiencing endoscopic treatment required retransplantation. ${ }^{12,13}$

In conclusion, our case is a great example of biliary cast syndrome, showing that long-standing biliary sludge may lead to cast formation.

\section{Conflicts of Interest}

The authors have no financial conflicts of interest.

\section{REFERENCES}

1. Starzl TE, Putnam CW, Hansbrough JF, Porter KA, Reid HA. Biliary complications after liver transplantation: with special reference to the biliary cast syndrome and techniques of secondary duct repair. Surgery 1977;81:212-221.

2. McMaster P, Herbertson BM, Cusick C, Calne RY, Syrakos T, Marni A. The development of biliary "sludge" following liver transplantation. Transplant Proc 1979;11:262-266.

3. Shah JN, Haigh WG, Lee SP, et al. Biliary casts after orthotopic liver transplantation: clinical factors, treatment, biochemical analysis. Am J Gastroenterol 2003;98:1861-1867.

4. Parry SD, Muiesan P. Cholangiopathy and the biliary cast syndrome. Eur J Gastroenterol Hepatol 2003;15:341-343.

5. D'Haens GR, Ruchim MA, Goldberg MJ, Baker AL. Massive intra-hepatic and extra-hepatic bile cast formation after cholecystectomy. Gastrointest Endosc 1993;39:579-581.

6. Byrne MF, Chong HI, O’Donovan D, et al. Idiopathic cholangiopathy in a biliary cast syndrome necessitating liver transplantation following head trauma. Eur J Gastroenterol Hepatol 2003;15:415-417.

7. Katsinelos P, Kountouras J, Chatzimavroudis G, Zavos C, Pilpilidis I, Paroutoglou G. Combined endoscopic and ursodeoxycholic acid treatment of biliary cast syndrome in a non-transplant patient. World J Gastroenterol 2008;14:5223-5225.

8. Gleeson FC, Czaja AJ, Baron TH. Successful endoscopic management of biliary cast syndrome in nonliver transplant patients. J Clin Gastroenterol 2008;42:752-755.

9. Dziurkowska-Marek A, Hartleb M, Marek TA, et al. Fatal case of biliary cast syndrome in nontransplant patient. Endoscopy 2009;41 Suppl 2: E256.

10. Hosoi M, Nannya Y, Sasaki T, et al. Biliary cast syndrome and benign biliary stricture as complications of allogeneic hematopoietic stem cell transplantation. Ann Hematol 2010;89:1287-1289.

11. Murray FE, Stinchcombe SJ, Hawkey CJ. Development of biliary sludge in patients on intensive care unit: results of a prospective ultrasonographic study. Gut 1992;33:1123-1125.

12. Pfau PR, Kochman ML, Lewis JD, et al. Endoscopic management of postoperative biliary complications in orthotopic liver transplantation. Gastrointest Endosc 2000;52:55-63.

13. Gholson CF, Zibari G, McDonald JC. Endoscopic diagnosis and management of biliary complications following orthotopic liver transplantation. Dig Dis Sci 1996;41:1045-1053. 